\title{
OMAE2017-61842
}

\section{STRAIN CAPACITY OF GIRTH WELDED JOINTS IN HSAW PIPES}

\author{
Koen Van Minnebruggen \\ Ghent University - EEMMeCS \\ Laboratory Soete \\ Zwijnaarde, Belgium
}

\author{
Stijn Hertelé \\ Ghent University - EEMMeCS \\ Laboratory Soete \\ Zwijnaarde, Belgium
}

\author{
Wim De Waele \\ Ghent University - EEMMeCS \\ Laboratory Soete \\ Zwijnaarde, Belgium
}

\begin{abstract}
The general aim of a recently finalized European project, i.e. EU RFCS SBD-Spipe, is to generate specific know-how concerning the development and possible use of spirally welded pipes for demanding applications. The demanding applications relate especially to structural integrity issues, both onshore and offshore, requiring good performance under application of large strains resulting in buckling, collapse and/or tensile loading. The outcome of this project can also be used as technical basis for improving standards and guidelines, that address design and safety of spirally welded pipelines.
\end{abstract}

The contribution of Ghent University to this project focusses on the aspects of tearing resistance, defect tolerance and strain capacity of girth welded joints subjected to remote axial tensile load. A numerical and experimental approach is used for the assessment of flaw tolerability and strain development upon tensile loading. Spiral pipes of steel grade API-5L X70 with 36" and 48" diameters have been girth welded using both a manual and semi-automatic welding processes. Curved wide plate specimens have been extracted from the pipes and artificial weld defects have been introduced. The specimens have been loaded in tension up to failure at a temperature of $-10^{\circ} \mathrm{C}$. This paper reports on the experimental result of a series of curved wide plate tests.

\section{INTRODUCTION}

Spiral welded pipes are employed in large-diameter pipeline applications for the transportation of hydrocarbons in strainbased design related projects due to economic benefits in comparison with traditionally used UOE pipes [1]. In the field of onshore pipelines, spiral welded pipes have gained large market shares, as an alternative to longitudinal seam welded pipes for oil and gas pipelines. However, there exists a debate on whether such pipes can also be considered for relatively shallow-water off-shore pipeline applications as well as in geohazard areas. As a result, spiral welded pipes have only limitedly been employed for demanding applications, e.g. in the $2^{\text {nd }}$ West-East China Pipeline.

Pipelines for oil and gas transportation in Strain Based Design related projects may experience high longitudinal strains from environmental events such as soil settlements and discontinuous permafrost. Since spiral welded pipes have economic advantages for these purposes, the structural response of these pipes when facing an environmentally imposed global plastic strain (SBD) is of critical importance. However, the use of such pipes in demanding pipeline applications is generally limited, especially for offshore pipelines, due to a lack of reliable technical data. A potential weak link is the girth weld connecting two pipe sections, which may contain weld flaws.

During the last years, significant work has been carried out to investigate the mechanical behavior of spiral welded pipes under combined bending and internal pressure, employing both experimental and numerical approaches. Eltaher et al. [2] investigated the response of spiral welded pipes to different loading combinations and particularly to S-lay conditions, qualifying spiral welded pipe for offshore shallow water applications. Van Es et al. [3, 4] conducted full-scale four-point bending tests on spirally welded tubes and reported valuable measurements on imperfection before the tests. The bending deformation response of large diameter spiral-welded tubes was also simulated numerically by Vasilikis et al. [5, 6], and a comparison was conducted with available test data. More recently, using parametric finite element analyses, Van Minnebruggen et al. [7] studied the influence of pipe forming angle, weld strength overmatch and material strength anisotropy on the tensile strain capacity of flawed spiral welded pipes.

The scope of this study is part of a large European RFCS (Research Fund for Coal and steel) project (SBD-SPIPE, 20132016) sponsored by the European Commission, aimed at examining the structural performance of the spiral welded pipes in offshore and onshore applications and the effect of spiral cold 
bending forming process. Within the full scope of the project, a combined numerical-experimental approach has been adopted. Focus of the numerical parts have been both on a complementary and a supplementary point of view related to the experimental part to broaden the observations and conclusions. For the experimental part, material with a X70 steel grade has been selected to obtain pipes which are representative for onshore and respectively offshore applications.

The contribution of Ghent University to this project focusses on the aspect of tearing resistance, defect tolerance and strain capacity of girth welded joints subjected to remote axial tensile load. A numerical and experimental approach has been used for the assessment of flaw tolerability and strain development upon tensile loading.

The experimental investigations were focused on the:

- Characterization of the longitudinal pipe metal and the all weld metal tensile properties;

- Determination of the Charpy impact properties of the weld metal and HAZ of the welds;

- $\quad$ Evaluation of tearing resistance based on SENT testing of weld and base material;

- Interaction between weld strength mismatch, defect size and longitudinal post-yield strain capacity of 300 mm wide tensile loaded weld centreline and HAZ notched curved wide plate (CWP) specimens;

Curved wide plate specimens have been extracted from the pipes and artificial weld defects have been introduced in the weld metal center and in the heat affected zone. They are loaded in tension up to failure at a temperature of $-10^{\circ} \mathrm{C}$. This paper will report on the experimental results of the curved wide plate tests.

Most CWP testing was completed with a semi-elliptical surface breaking notch having a maximum depth of $4 \mathrm{~mm}$ and a length equal to 5 times the wall thickness. Additional tests with artificial defects measuring $4 \mathrm{~mm}$ by $50 \mathrm{~mm}$ (notch length related to workmanship criteria) were completed to evaluate the sensitivity to notch dimensions and to validate the recommended EPRG defect limits [8].

\section{BACKGROUND}

Girth weld integrity is a key factor in ensuring safe pipeline behavior. Traditionally, designers strive to develop consumable / weld procedure combinations maximizing weld metal toughness to ensure safe girth welds. If a weld defect occurs detailed analysis of historical curved wide plate (CWP) data allows concluding that many more material properties affect the strain capacity of flawed girth welds under tensile load [9]. The failure characteristics of a flawed girth weld also depend on:

- the defect (flaw) size (length and height) and defect location;

- the post yield stress-strain response (strain hardening characteristics, uniform elongation capacity, ...) of the materials in the flawed (weld) region and the (remote) pipe sections;

- $\quad$ the level of yield and flow strength mismatch;

- the geometry of the weld bevel and weld reinforcement;

- the wall thickness variations,

- the ductile tearing characteristics of the material in the flawed region, etc.

Thus, the quantification of the tensile strain capacity of pipeline girth welds with natural or artificial flaw requires a test configuration allowing the assessment of these variables. The CWP test is a conservative means, relative to full-scale bend testing, of producing representative information [10].

Considering its capabilities, the CWP test has in the last decade developed into a widely applied testing technique for [11]:

- determining the post yield characteristics and the maximum (limit) strain capacity of girth welds studying phenomena (tearing behavior, strength mismatch, ..) that cannot simply be modeled,

- $\quad$ optimizing material requirements for stress and strain based designs,

- validation of stress and strain based design defect acceptance criteria,

- validating numerical models/defect assessment concepts, etc.

In this study, as mentioned earlier, the prime objective of the investigations was to study the interaction between toughness, weld strength mismatch and CWP test behavior of flawed girth welds in HSAW steel pipes.

\section{PIPE MATERIALS AND WELDING}

Pipe materials - Two pipes are considered, made of X70 grade steel. The first pipe has a diameter and thickness equal to $914 \mathrm{~mm}$ (36 in) and 17.1mm respectively, the second pipe has a diameter equal to $711 \mathrm{~mm}$ (28 in) and thickness 18mm. Both pipes are provided by Salzgitter Mannesmann Forschung $\mathrm{GmbH}$ (SZMF). Each pipe was cut in 8 pup-pieces and re-jointed by girth welding. This resulted in two times four girth welded pipe sections.

Welding - For each pipe, the four girth welds have been produced using two manual welding and two semi-automatic welding procedures, see Fig 1. For each welding procedure, a weld strength overmatch between $+0 \%$ to $+10 \%$ and between $+10 \%$ to $+30 \%$ was targeted. The rationale of this choice was to demonstrate that (highly) overmatched welds have a beneficial effect on the longitudinal strain capacity. The weld combinations studied in this investigation are identified in Table 1. The puppieces were welded by Instytut Spawalnictwa, Poland.

In figure 1, the hardness mappings are illustrated by means of two examples. Based on these mappings, a clear distinction in 
different material properties can be localized for the base material, different welding passes, and HAZ. Automatic welds are shown to be more homogeneous. The manual welds tend to have significant differences between root and cap and tend to be more susceptible to HAZ softening.

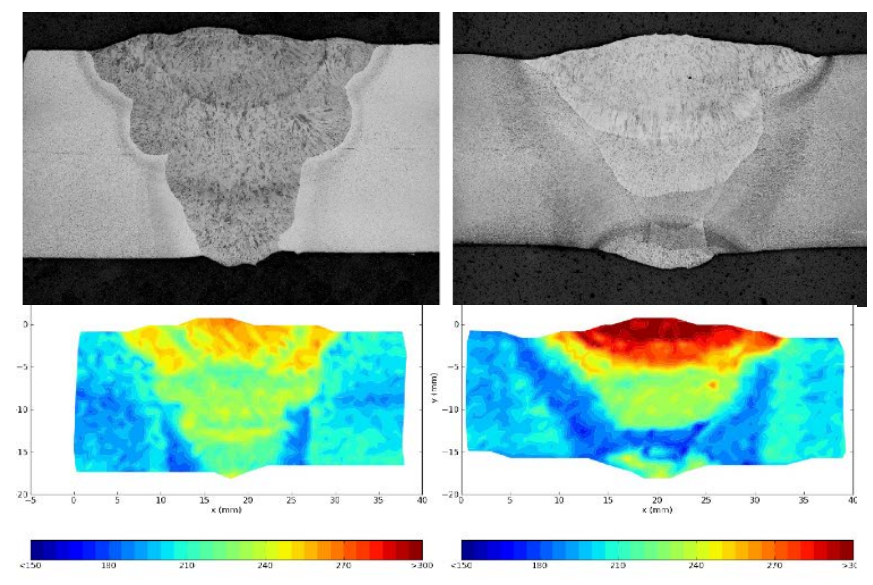

Figure 1: Typical weld macro sections (left automatic, right manual). Bottom: Vickers hardness mapping [150HV5 - 300HV5]

These hardness mapping are found to be valuable for the in detailed analysis of the large and small scale test results. This is especially the case for the verification of notch positioning with respect to potentially weaker or brittle zones and for the evaluation of tearing behavior. These hardness mappings are performed for each CWP, but are not detailed described as this is beyond the scope of this paper.

Table 1: Weld combinations

\begin{tabular}{|c|c|c|}
\hline Weld \# & Welding process & Target overmatch \\
\hline SB4 & Manual & $0 \rightarrow+10 \%$ \\
\hline SB3 & Manual & $+10 \% \rightarrow+30 \%$ \\
\hline SB2 & Automatic & $0 \rightarrow+10 \%$ \\
\hline SB1 & Automatic & $+10 \% \rightarrow+30 \%$ \\
\hline SA4 & Manual & $0 \rightarrow+10 \%$ \\
\hline SA2 & Manual & $+10 \% \rightarrow+30 \%$ \\
\hline SA1 & Automatic & $0 \rightarrow+10 \%$ \\
\hline SA3 & Automatic & $+10 \% \rightarrow+30 \%$ \\
\hline
\end{tabular}

Table 1 is limited to the target overmatch values for each pipe section. The actual material and overmatch properties are listed in Tables 3 through 5.

\section{TESTING DETAILS}

Specimen sampling - The standard properties of the welded pup-pieces were determined from pipe metal and all-weld tensile, Charpy V (CVN) notch impact toughness, and tearing resistance SENT tests. The failure characteristics were determined by CWP tensile tests. As shown in Figure 2, the CWP specimens were not flattened for testing.

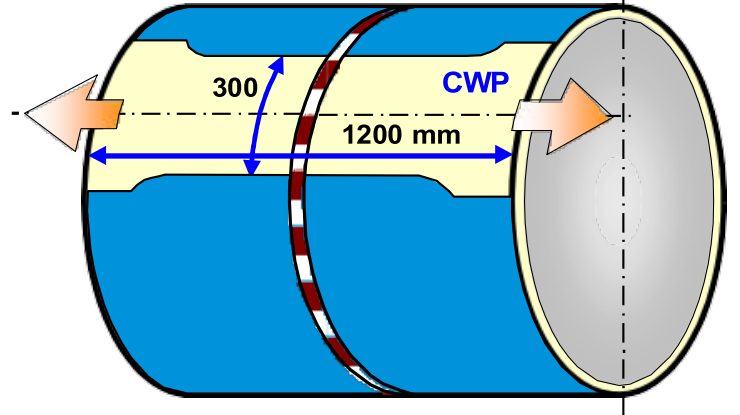

Figure 2: CWP specimen

The small-scale and CWP specimen test blanks were extracted at several positions around the pipe circumference to produce information on the variation of the pipe and girth weld properties around the pipe circumference, Figure 3. Each of the 8 welds were subjected to the same test matrix, Table 3 . The figure also illustrates 2 medium wide plates (MWP) which are CWP with a prismatic width of $150 \mathrm{~mm}$. The test results of these specimens are not discussed within this paper. The curved wide plates were extracted in the longitudinal (axial) direction.

Table 2: Testing matrix for each of the eight weld combinations

\begin{tabular}{|c|c|c|}
\hline Type of test & Details & Number of tests \\
\hline $\begin{array}{l}\text { Pipe metal } \\
\text { tensile }\end{array}$ & Axial direction & 6 \\
\hline $\begin{array}{l}\text { All weld } \\
\text { tensile }\end{array}$ & - & 3 \\
\hline Crossweld & Axial direction & 3 \\
\hline MWP & Medium CWP & 2 \\
\hline SENT & $\begin{array}{l}\text { Notch location in } \\
\text { weld center }\end{array}$ & 3 \\
\hline $\begin{array}{c}\text { Vickers } \\
\text { hardness }\end{array}$ & Mapping & 3 \\
\hline Charpy V & \multirow{2}{*}{$\begin{array}{l}\text { Notch location: } \\
\text { HAZ/FL and } \\
\text { Weld metal center }\end{array}$} & 18 \\
\hline CWP & & 3 \\
\hline
\end{tabular}

The pipe metal, all-weld metal and Charpy test pieces were taken from cut-away portions immediately adjacent to each wide plate specimen to ensure that the strength and notch toughness properties of each CWP specimen were characterized as accurately as possible, Figures 4 and 5 . 


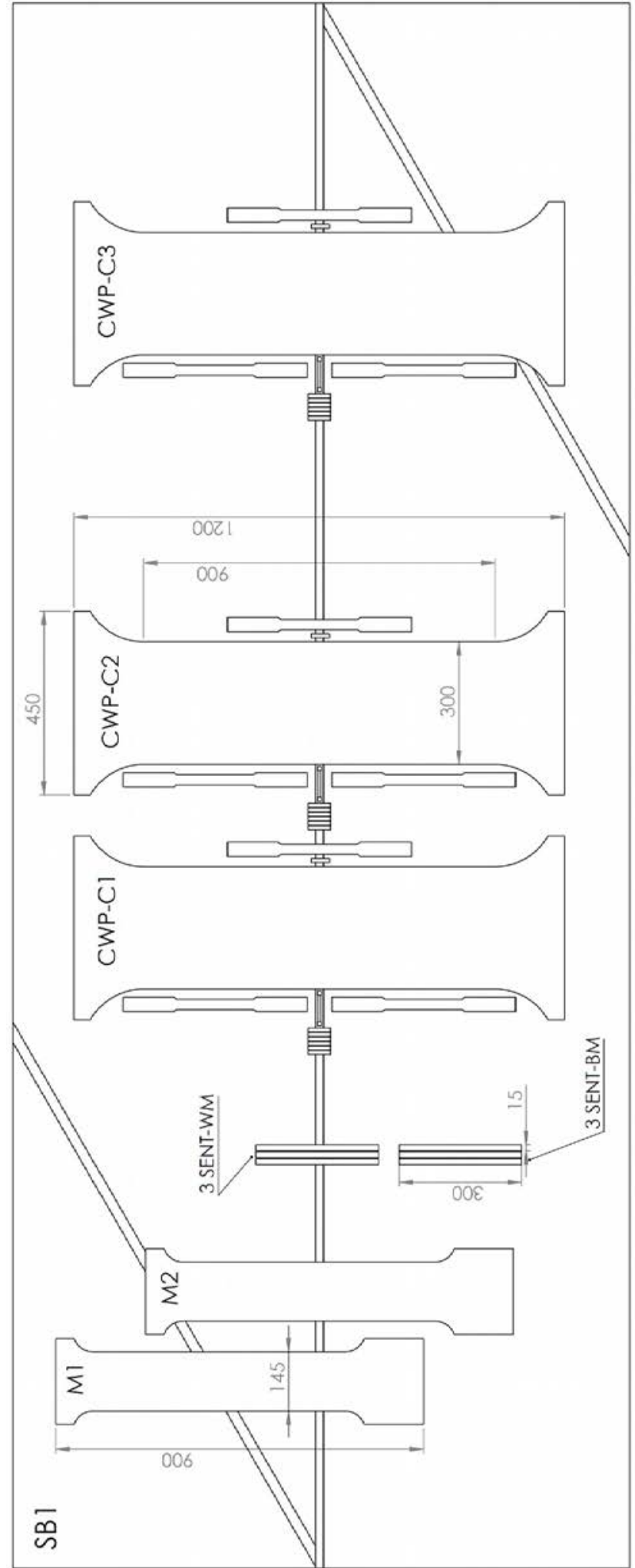

Figure 3: CWP specimen sampling positions

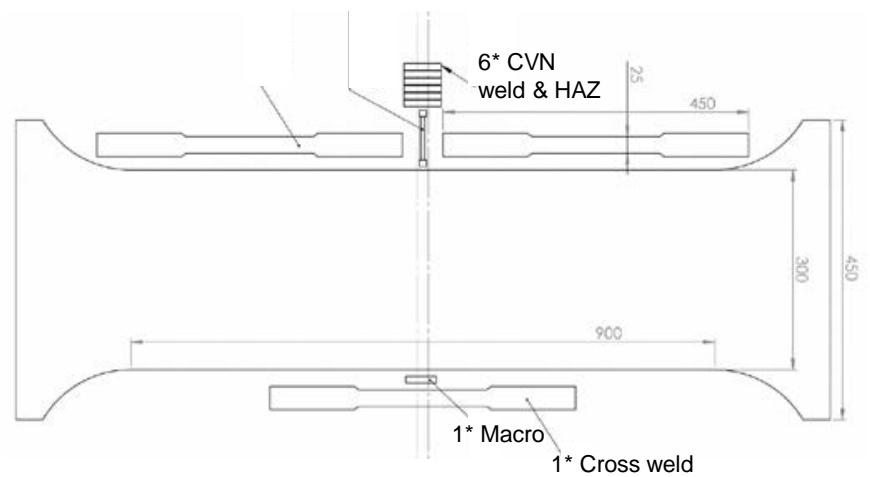

Figure 4: Illustration of small scale specimens sampling positions.

Standard small-scale tensile tests - The pipe metal and allweld tensile tests were performed to (a) verify whether the measured properties complied with the requirements, (b) determine the actual levels of weld metal flow strength (i.e. average of yield and tensile strength) mismatch and (c) assist the interpretation of the CWP test results. To determine the uniform elongation (uEL) or the strain at ultimate strength, the full stressstrain curves were also generated for each of these tensile tests.

The longitudinal pipe tensile properties were measured using flat-strip dogbone shaped specimens with a reduced section of $200 \mathrm{~mm}$ long and $25 \mathrm{~mm}$ wide. Uniform elongation was measured over a $50 \mathrm{~mm}$ gauge length. All-weld metal tensile testing was conducted using a round bar $(\Phi 6 \mathrm{~mm})$ geometry with threaded ends. These tensile test have been performed according to DIN 50125 and ASTM A370. The test section was positioned near the mid-thickness of the fill passes.

Crosswelds were performed to identify the weakest link upon loading to differentiate between failure locations, i.e. base material, FL/HAZ or weld material.

Toughness tests - The weld metal and HAZ/FL notch and fracture toughness properties were determined by Charpy $\mathrm{V}$ $(\mathrm{CVN})$ testing with triplicate specimens at $-10^{\circ} \mathrm{C}$. All CVN specimens were transverse to the girth weld. The notch orientation was the same as for the CWP tests. The full size (10 $\mathrm{mm} * 10 \mathrm{~mm}$ ) CVN specimens were taken $1 \mathrm{~mm}$ subsurface at the root side of the weld. The CVN tests were performed according EN 10045 Part 1.

Tearing resistance SENT tests - The weld metal and base material have been evaluated in terms of tearing resistance upon tensile loading using SENT tests. The specimens had a cross section of $15 \mathrm{~mm} * 15 \mathrm{~mm}$ with daylight grip length of $150 \mathrm{~mm}$.

CWP tests -The CWP specimens had an overall length of $1200 \mathrm{~mm}$ (with the girth weld at mid-length) and a width (arc length) of $440 \mathrm{~mm}$. The test section was $900 \mathrm{~mm}$ long by 300 $\mathrm{mm}$ wide. The girth weld was located in the middle of the test section. The weld reinforcements at either side were not 
removed, except at the root side where the artificial notch was made. Figure 5 details the specimen geometry and the instrumentation (CMOD and elongation measurements) applied.

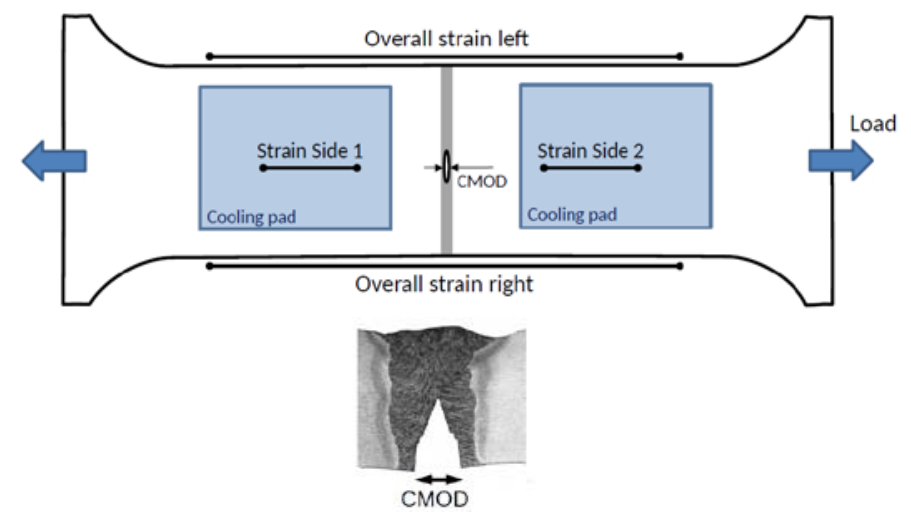

Figure 5: Instrumentation of CWP specimen

The overall elongation (gauge length of $750 \mathrm{~mm}$ straddling the weld and the notch at mid-span), the pipe metal elongations (gauge length: $200 \mathrm{~mm}$ ) and the CMOD or crack mouth opening on a gauge length of $8 \mathrm{~mm}$ straddling the notch at mid-length, were measured. The remote pipe metal elongation was measured using LVDT's with gauge length of $200 \mathrm{~mm}$.

The surface-breaking notch of 5 times the wall thickness long by $4 \mathrm{~mm}$ high was, using a sharp cutting wheel, introduced either at the weld metal centerline (WMC) or HAZ. The notch tip acuity was $0.15 \mathrm{~mm}$. As CWP testing progressed, shorter notches were tested to gather information on notch size effects. The length of the shortest notch was approx. 3*t or $50 \mathrm{~mm}$ (where $t$ is the wall thickness). This defect length corresponds to the EPRG maximum allowable defect length ensuring remote yielding [8].

The CWP specimens were strained (under displacement control) to failure or maximum load instability at $-10^{\circ} \mathrm{C}$. Cooling was achieved by circulating chilled ethyl-methyl alcohol through chambers clamped onto the specimen. Figure 6 shows a CWP specimen (welded to heavy end plates) mounted in the load frame of the $8000 \mathrm{kN}$ tensile machine and cooling chambers.

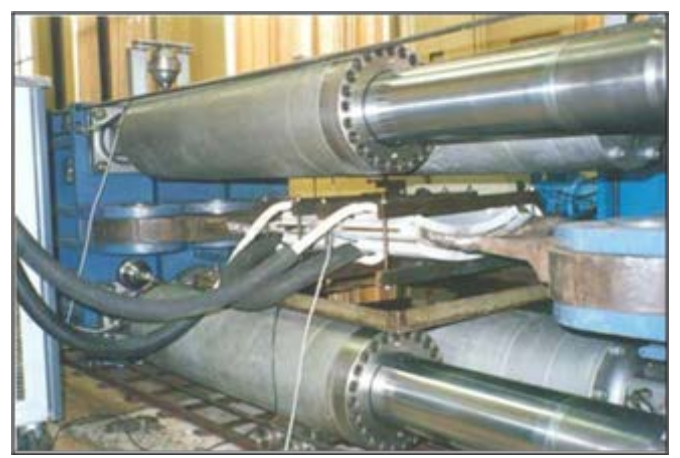

Figure 6: Cooled CWP specimen mounted in the 8000 $\mathrm{KN}$ load frame ready for tensile testing.
Upon completion of testing, the load and CMOD versus elongation records were used to determine the gross section stress, the overall remote pipe metal strain, the pipe metal strains of both pipes and CMOD at either the occurrence of maximum load instability or unstable fracture initiation. In addition, the notches, fracture faces and macro sections through the flawed area were photographed. The pictures of the macro sections were used to verify whether the notch tip effectively intercepted the target microstructure. The procedures of this investigation are detailed in reference [9].

\section{PIPE AND WELD METAL TENSILE PROPERTIES}

The pipe and all-weld metal tensile properties of the eight girth welds involved in the study are shown graphically in Tables 3 through 5.

Pipe metal tensile properties - The base metal yield strengths and tensile properties are compared in Table 3. It is observed that both pipes SA and SB have a high strength level within the X70 steel grade. Additionally, both pipes are found to have a yield-to-tensile ratio between 0.89 and 0.92 , which is a high value for a strain-based design approach. These challenging material conditions were deliberately targeted to obtain trustworthy results.

Table 3: Base material stress-strain properties

\begin{tabular}{|c|c|c|c|c|c|}
\hline & $\begin{array}{c}\text { Yield } \\
\text { stress } \\
\left(\mathbf{R}_{\mathbf{p 0}, 2}\right) \\
{[\mathbf{M P a}}\end{array}$ & $\begin{array}{c}\text { Tensile } \\
\text { strength } \\
{[\mathbf{M P a}]}\end{array}$ & $\begin{array}{c}\text { Flow } \\
\text { stress } \\
{[\mathbf{M P a}]}\end{array}$ & $\begin{array}{c}\text { Y/T } \\
{[-]}\end{array}$ & $\begin{array}{c}\text { Uel } \\
{[\%]}\end{array}$ \\
\hline SB4 & 607 & 660 & 633 & 0.918 & 7.33 \\
\hline SB3 & 585 & 637 & 611 & 0.919 & 6.59 \\
\hline SB2 & 575 & 626 & 600 & 0.920 & 6.31 \\
\hline SB1 & 601 & 655 & 628 & 0.917 & 7.01 \\
\hline SA4 & 588 & 660 & 624 & 0.891 & 6.48 \\
\hline SA2 & 566 & 639 & 602 & 0.886 & 6.50 \\
\hline SA1 & 580 & 647 & 613 & 0.897 & 7.00 \\
\hline SA3 & 572 & 643 & 607 & 0.889 & 6.32 \\
\hline
\end{tabular}

All-weld metal tensile properties - The all-weld metal yield strengths and tensile properties are compared in Table 4.

Table 4: Weld material stress-strain properties

\begin{tabular}{|c|c|c|c|c|c|}
\hline & $\begin{array}{c}\text { Yield } \\
\text { stress } \\
{[\mathbf{M P a}]}\end{array}$ & $\begin{array}{c}\text { Tensile } \\
\text { strength } \\
{[\mathbf{M P a}]}\end{array}$ & $\begin{array}{c}\text { Flow } \\
\text { stress } \\
{[\mathbf{M P a}]}\end{array}$ & $\begin{array}{c}\text { Y/T } \\
{[-]}\end{array}$ & $\begin{array}{c}\text { Uel } \\
{[\%]}\end{array}$ \\
\hline SB4 & 579 & 650 & 615 & 0.891 & 8.48 \\
\hline SB3 & 620 & 732 & 676 & 0.848 & 6.58 \\
\hline SB2 & 641 & 749 & 695 & 0.857 & 8.73 \\
\hline SB1 & 711 & 818 & 765 & 0.869 & 7.40 \\
\hline SA4 & 616 & 724 & 670 & 0.851 & 9.98 \\
\hline SA2 & 674 & 777 & 726 & 0.868 & 6.46 \\
\hline SA1 & 630 & 749 & 690 & 0.841 & 10.50 \\
\hline SA3 & 752 & 850 & 801 & 0.884 & 8.68 \\
\hline
\end{tabular}


Yield strength mismatch - Comparison of the flow strength of pipe and weld material confirms that the mismatch is attained as desired for the majority of the welds, Table 5. It should be noted that pipe section SB4 exhibits an undesired strength undermatch of $3 \%$, resulting in a weld cross-tension failure location in the weld region. The weld cross tension tests from the other pipe sections confirm that the weakest link is not located in the weld region.

Table 5: Flow strength mismatch and weld cross-tension

\begin{tabular}{|c|c|c|}
\multicolumn{1}{|c|}{} & $\begin{array}{c}\text { Mismatch } \\
{[\%]}\end{array}$ & Failure location \\
\hline SB4 & -3.0 & HAZ/FL and weld region \\
\hline SB3 & 10.6 & remote, i.e. base material \\
\hline SB2 & 15.7 & remote, i.e. base material \\
\hline SB1 & 21.7 & remote, i.e. base material \\
\hline SA4 & 7.3 & remote, i.e. base material \\
\hline SA2 & 20.5 & remote, i.e. base material \\
\hline SA1 & 12.4 & remote, i.e. base material \\
\hline SA3 & 31.9 & remote, i.e. base material \\
\hline
\end{tabular}

\section{TOUGHNESS PROPERTIES}

The measured CVN impact energies were compared with the EPRG toughness requirements of $30 \mathrm{~J}$ minimum and 40J average [8]. Table 6 illustrates that the minimum and mean weld metal and HAZ CVN energies satisfied the EPRG requirements by a fair margin. It has been shown that the 30 (min.) / 40 (mean) $\mathrm{J}$ requirement typically excludes brittle fracture, it can be expected that failure by remote yielding (e $>0,5 \%$ ) will occur for prescribed defect sizes [8].

Table 6: Charpy V-notch impact energy at $-10^{\circ} \mathrm{C}$

\begin{tabular}{|c|c|c|c|c|}
\hline & \multicolumn{2}{|c|}{ Weld metal } & \multicolumn{2}{c|}{ HAZ/FL region } \\
\hline & Min. [J] & Avg. [J] & Min. [J] & Avg. [J] \\
\hline SB4 & 73 & 112 & 78 & 129 \\
\hline SB3 & 39 & 76 & 33 & 79 \\
\hline SB2 & 64 & 82 & 65 & 107 \\
\hline SB1 & 53 & 65 & 51 & 92 \\
\hline SA4 & 71 & 89 & 61 & 98 \\
\hline SA2 & 53 & 63 & 30 & 70 \\
\hline SA1 & 86 & 98 & 73 & 102 \\
\hline SA3 & 59 & 73 & 52 & 83 \\
\hline
\end{tabular}

The lowest minimum CVN values (30J and 39J) were measured in both the HAZ/FL and weld metal. There is a limited difference observed between the various weld conditions, and thus had little effect on HAZ/FL CVN impact energy.

The tearing resistance properties obtained by SENT-testing are listed in Table 7. Here, it can be observed that both weld and base material show an adequate tearing behavior. Tearing resistance is described by following equation which relates the crack tip opening displacement (CTOD) to the crack extension $(\Delta \mathrm{a})$ :

$$
\mathrm{CTOD}=\delta_{1} * \Delta \mathrm{a}^{\delta 2}
$$

Table 7: Tearing resistance properties

\begin{tabular}{|c|c|c|}
\hline & $\boldsymbol{\delta}_{\mathbf{1}}$ & $\boldsymbol{\delta}_{\mathbf{2}}$ \\
\hline SB4 & 1.20 & 0.64 \\
\hline SB3 & 1.13 & 0.40 \\
\hline SB2 & 0.81 & 0.63 \\
\hline SB1 & 1.18 & 0.55 \\
\hline SA4 & 1.18 & 0.52 \\
\hline SA2 & 1.33 & 0.88 \\
\hline SA1 & 1.13 & 0.56 \\
\hline SA3 & 1.01 & 0.63 \\
\hline Base material pipe A & 1.93 & 0.38 \\
\hline Base material pipe B & 2.16 & 0.36 \\
\hline
\end{tabular}

In Figure 7, an example of a tearing resistance curve is provided for weld condition SB4. The tearing resistance curve was experimentally determined by a single-specimen technique using the direct current potential drop technique, as detailed by Verstraete et al. [12].

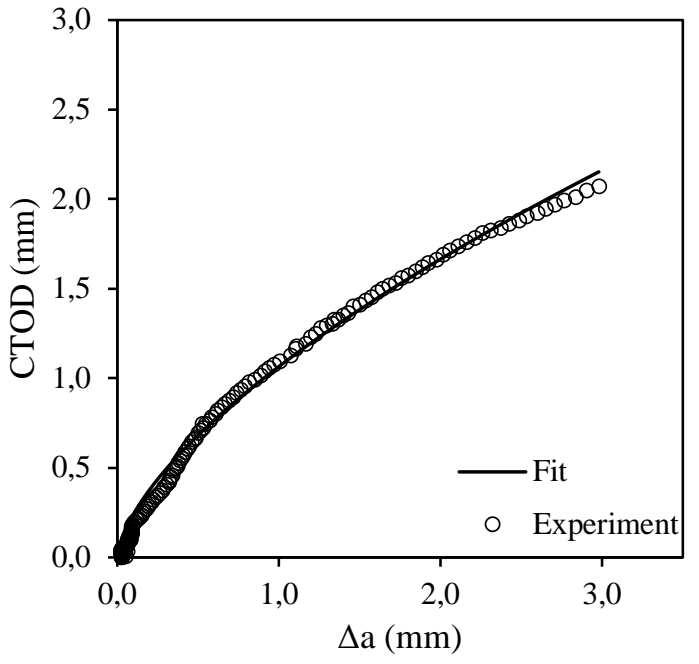

Figure 7: Example of tearing resistance curve (e.g. for weld SB4)

\section{WIDE PLATE TEST RESULTS}

The strain versus weld strength mismatch levels are graphically illustrated in Figures 8 and 9. 


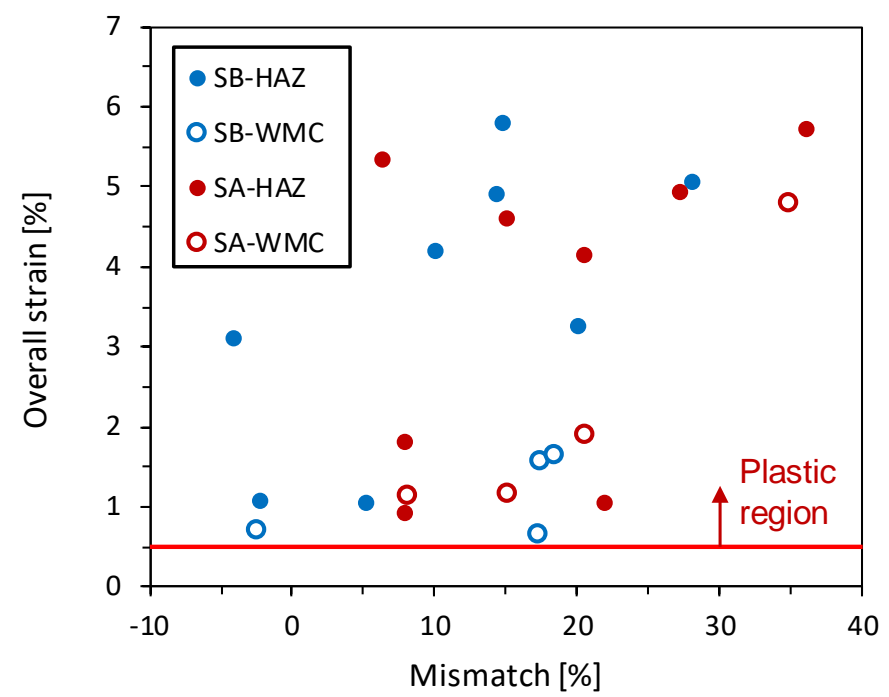

Figure 8: Strain versus mismatch: Pipe A versus pipe B

Based on Figure 8, it is observed that both pipes show a similar scatter pattern on the graph. A significant amount of CWP tests resulted in a significant remote yielding well beyond the plastic region. Even for the under- and evenmatched weld conditions, some CWP fail after significant straining. It should however be noted that, for some CWP tests with a high overmatch level, the strain behavior is adequate (i.e. above $0.5 \%$ ) but not high, as would be expected from the high overmatch levels. This can partly be attributed to the notch size influence, as illustrated in Figure 9.

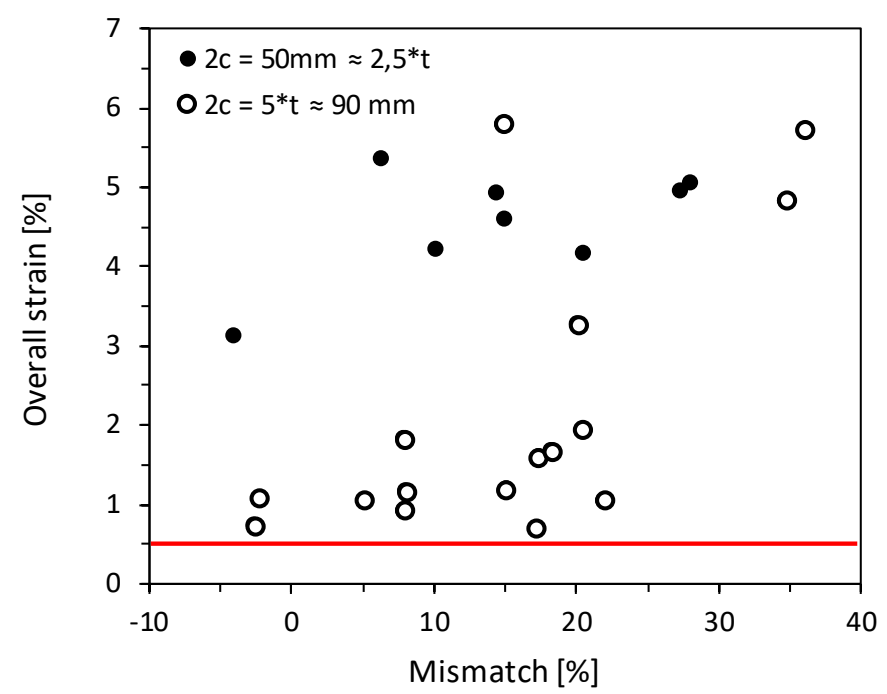

Figure 9: Strain versus mismatch: Influence of notch length

Figure 9 shows as expected that a larger notch reduces the remote strain. However, it does not fully clarify the non-linear relation between mismatch and strain behavior. Here, the toughness properties show to have a significant influence. The
CWP specimens with an undermatching or evenmatching weld strength that show a high strain behavior are found to have a high charpy impact toughness and an adequate tearing resistance. The CWP tests with a high overmatch and a lower strain behavior are found to have a lower charpy impact energy (i.e. approx. 50J). It should additionally be mentioned that the geometrical reinforcement was not taken into account in the above graph, which will shift the actual mismatch level in a positive direction.

Although, some of the notch dimensions were very severe, i.e. $4 \mathrm{~mm} \times 90 \mathrm{~mm}$, the majority of the plates failed well beyond the elastic region. For notch lengths of $50 \mathrm{~m}$, which is detectable by NDT, we see a high tolerability in term of plastic strain. These observations give confidence in the suitability of spiral welded pipes in a strain based design. Especially given the deliberately not favorable conditions of the base material properties. To this respect, it can be concluded that HSAW CWP tests do not underperform compared to LSAW CWP's.

\section{SUMMARY AND CONCLUSIONS}

Small-scale testing (tensile, Charpy V and SENT tearing resistance) and curved wide plate (CWP) tensile tests have been performed to determine the failure characteristics of eight girth welds in X70 pipes. Four pipe sections have a diameter and thickness equal to $914 \mathrm{~mm}$ (36 in) and $17.1 \mathrm{~mm}$ respectively, the other four pipe sections have a diameter equal to $711 \mathrm{~mm}$ (28 in) and thickness $18 \mathrm{~mm}$. Manual and semi-automatic welding procedures were applied to obtain a flow strength overmatch of $0 \%$ to $+10 \%$ and $+10 \%$ to $+30 \%$. All welds were subjected to an extensive test matrix to quantify the effects of weld metal (notch and fracture) toughness, weld metal strength mismatch and defect size on the longitudinal straining capacity. The toughness and CWP tests were performed at $-10^{\circ} \mathrm{C}$.

The results of the pipe / weld combinations tested support the following observation that all CWP tests failed beyond remote plastic yielding. This was the case for all conditions even for the specimens with a low weld strength overmatch as a result of the high tearing resistance confirmed by SENT testing. For the specimens with a large defect size, in combination with the low toughness, the remote yielding is reduced even though some of these specimens had a significant weld strength overmatch. It was observed that for NDI detectable defect sizes with a length of $50 \mathrm{~mm}$, large remote strains are allowable, even so for weld conditions with a low overmatch level. It can thus be concluded based on the investigated data-set that HSAW CWP tests perform comparable to LSAW CWP tests.

\section{ACKNOWLEDGMENTS}

The research work described in this paper was carried out with a financial grant from the European Commission through the Research Fund for Coal and Steel, Contract RFSR-CT-201300025, "Strain-Based Design of Spiral-Welded Pipes for Demanding Pipeline Applications”, acronym SBD-SPIPE. 


\section{REFERENCES}

[1] Bian, Y., Penniston, C., Collins, L., \& Mackenzie, R. (2010). "Evaluation of UOE and Spiral-Welded Line Pipe for Strain Based Designs". Proceedings of the Biennial International Pipeline Conference, IPC2010-31315, Calgary, Alberta, Canada.

[2] Eltaher, A., Jafri, S., Jukes, P., \& Heiberg, G. (2012). "Advanced Finite Element Analysis for Qualification of Spiral Welded Pipe for Offshore Application”. Proceedings of the International Offshore and Polar Engineering Conference, ISOPE, Vol 4, pp. 303-310, Rhodes, Greece.

[3] Van Es, S. H. J., Gresnigt, A. M., Kolstein, M. H., \& Bijlaard, F. S. K. (2013). "Local Buckling of Spirally Welded Tubes - Analysis of Imperfections and Physical Testing”. Proceedings of the International Offshore and Polar Engineering Conference, ISOPE, Anchorage, Alaska, USA, Vol 2, pp. 248259.

[4] Van Es, S. H. J., Gresnigt, A. M., Vasilikis, D., Karamanos, S. A., (2016). "Ultimate bending capacity of spiralwelded steel tubes - Part I: Experiments". Thin-Walled Structures, Vol. 102, pp. 305-319, May 2016.

[5] Vasilikis, D., Karamanos, S. A., Van Es, S. H. J., \& Gresnigt, A. M. (2014). "Bending Deformation Capacity of Large-Diameter Spiral-Welded Tubes". Proceedings of the Biennial International Pipeline Conference, IPC2014-33231, Calgary, Alberta, Canada.

[6] Vasilikis, D., Karamanos, S. A., Van Es, S. H. J. and Gresnigt, A. M., "Ultimate Bending Capacity of Spiral-Welded Steel Tubes - Part II: Predictions”, Thin-Walled Structures, Vol. 102, pp. 305-319, May 2016.
[7] Van Minnebruggen, K., Hertelé, S., Thibaux, P., \& De Waele, W. (2015). "Effects of Specimen Geometry and Anisotropic Material Response on the Tensile Strain Capacity of Flawed Spiral Welded Pipes”. Engineering Fracture Mechanics, Vol. 148, pp 350-362

[8] Denys, R. M., Andrews, R. M., Zarea, M. and Knauf,G. (2009) "Recommended Revisions of the EPRG Tier 2 Guidelines for the Assessment Of Defects In Transmission Pipeline Girth Welds”, Proceeding of the Fifth Pipeline Technology Conference, Oostende.

[9] Denys R.M., Lefevre A.A., (2009) 'UGent Guidelines For Curved Wide Plate Testing', Proceedings Pipeline Technology Conference, October, Ostend, Belgium, Ed. R.Denys.

[10] Hopkins, P., and Denys, R.M., (1993) "The Background to the European Pipeline Research Group's Girth Weld Limits for Transmission Pipelines,” EPRG/NG-18, 9th Biennial Joint Technical Meeting on Line Pipe Research, Houston, Texas, 1993

[11] Hukle, M.V., Horn, A.M, Hoyt, D.S. and LeBleu, Jr., J.B., (2005) "Girth weld qualification for high strain pipeline applications”, ASME, Int. Conf. on OMAE, OMAE2005-67573, pp. 1-6.

[12] Verstraete, M.A., De Waele, W., Van Minnebruggen, K., and Hertelé, S. (2015). "Single-specimen evaluation of tearing resistance in SENT testing”. Engineering Fracture Mechanics, Vol 148, pp 324-336. 